\title{
Congenital Herniation of the Gyrus Rectus Resulting in Compressive Optic Neuropathy
}

\author{
Kia Gilani, Pejman Jabehdar Maralani, Arun NE Sundaram
}

Keywords: Compressive, Optic neuropathy, Congenital, Gyrus rectus, Neuro-ophthalmology

doi:10.1017/cjn.2020.136

Can J Neurol Sci. 2020; 47: 820-821

We report a 34-year-old male with a previously uninvestigated lifelong blindness of the right eye from compressive optic neuropathy secondary to congenital herniation of the gyrus rectus (HGR). His past medical history was otherwise unremarkable, with no history of prior head or ocular trauma. On examination, he had no light perception in the right eye, right relative afferent pupillary defect (RAPD), and primary optic atrophy. His left eye had normal visual acuity, color vision, and a healthy optic disc. There was a sensory exotropia in the right eye; however, extraocular movements were intact and the remainder of his neurological exam was normal. MRI revealed compression of the prechiasmatic right optic nerve from HGR and atrophy of the right optic nerve and optic chiasm (Figures 1 and 2), without any parenchymal mass lesions. There were no signal abnormalities in the optic nerves or the chiasm.

The gyrus rectus is located in the floor of the anterior cranial fossa superior to the prechiasmatic optic nerves and the optic chiasm. ${ }^{1}$ The posterior aspect of the gyrus rectus lies directly above the anterior aspect of the optic chiasm. ${ }^{2}$ Downward HGR can cause compression of the optic nerve, ${ }^{3}$ and more a posterior herniation into the suprasellar cistern can also compress the optic chiasm. ${ }^{4}$ Mass lesions arising from the frontal lobe can cause an acquired HGR and result in optic atrophy of the ipsilateral side

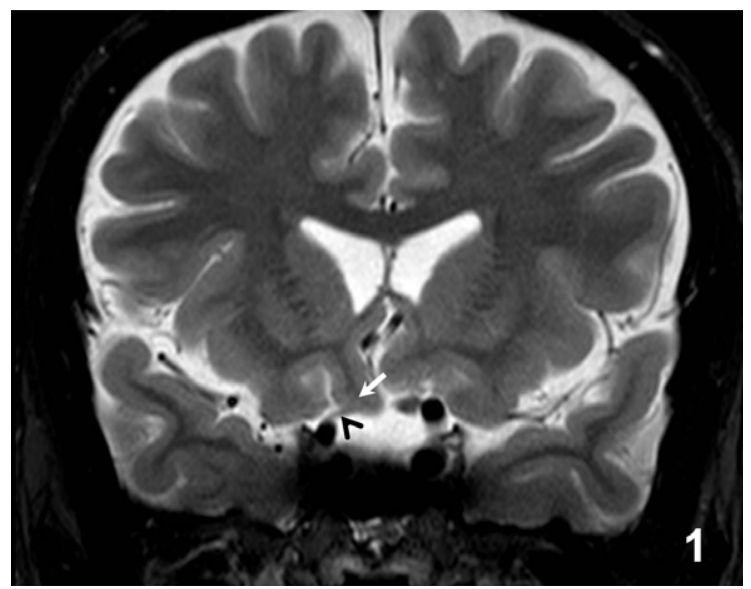

Figure 1: Coronal T2 weighted image demonstrates inferior herniation of the right gyrus rectus (white arrow) with compression and inferior displacement of the pre-chiasmatic optic nerve (black arrowhead). The optic nerve is atrophic.

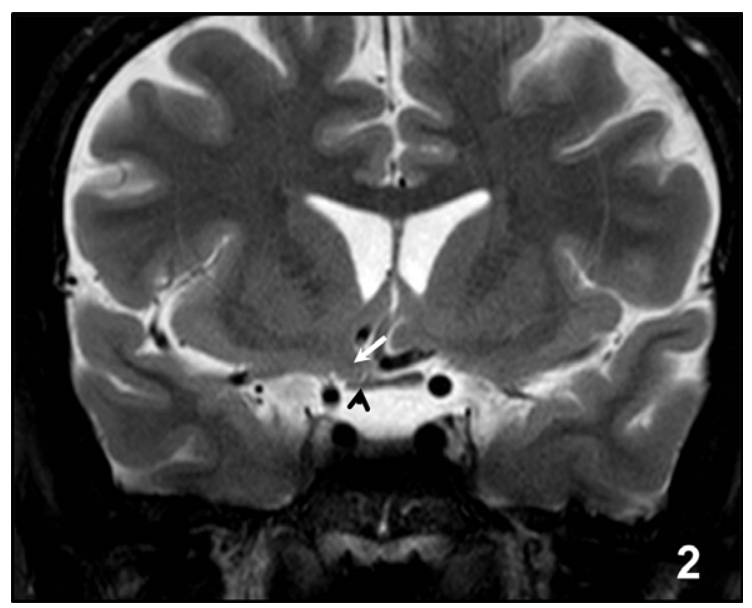

Figure 2: Coronal T2 weighted image shows optic chiasm atrophy on the right side (black arrowhead). White arrow points to the herniated right gyrus rectus.

and papilledema due to raised intracranial pressure in the fellow eye. This entity is called Foster Kennedy Syndrome. ${ }^{5}$ Acquired compressive optic neuropathy from idiopathic HGR has also rarely been reported. ${ }^{1}$

Compressive optic neuropathies must be considered in the differential diagnosis of painless visual loss in the clinical context of optic atrophy and RAPD. In most circumstances, compressive optic neuropathies typically present as a protracted course of gradually worsening visual loss. ${ }^{6}$ An exception to this typical clinical presentation is the rarely described cases of congenital optic nerve compression that present with blindness in childhood. ${ }^{7}$ Previously described compressive optic neuropathies include aneurysm ${ }^{8}$ and ectatic internal carotid artery. ${ }^{9}$ To our knowledge, this is the first case of congenital HGR causing compressive optic neuropathy.

From the Department of Medicine, Division of Neurology, University of Toronto, Toronto, Ontario, Canada (KG, ANES); Department of Medical Imaging, University of Toronto, Toronto, Ontario, Canada (PJM); and Department of Ophthalmology and Vision Sciences, University of Toronto, Toronto, Ontario, Canada (ANES)

Received December 21, 2019. Final Revisions Submitted May 15, 2020. Date of AcCeptance June 29, 2020.

Correspondence to: Arun N. E. Sundaram, Sunnybrook Health Sciences Centre, 2075 Bayview Avenue, M1 202c, Toronto, Ontario, Canada, M4N 3M5. Email: arun. sundaram@sunnybrook.ca 


\section{CONFLict OF INTEREST}

The authors do not have any conflicts of interests to declare.

\section{Statement of Authorship}

KG wrote the manuscript; PJM reviewed the MRI of the patient and provided labeled figures; ANES provided consultation and diagnosis for the patient and supervised the manuscript.

\section{REFERENCES}

1. Smith J, Jack MM, Peterson JC, Chamoun RB. Herniated gyrus rectus causing idiopathic compression of the optic chiasm. Clin Neurol Neurosurg. 2017;153:79-81.

2. Baka JJ, Spickler EM. Normal imaging anatomy of the suprasellar cistern and floor of the third ventricle. Semin Ultrasound CT MR. 1993;14(3):195-205.
3. Okumura R, Ishikawa M, Kondo A, Masai H, Ueki M, Suga K. Prolapsing gyrus rectus as a cause of progressive optic neuropathy. Neurol Med Chir (Tokyo). 2000;40(6):301-9.

4. Klingele TG, Gado MH, Burde RM, Coxe WS. Compression of the anterior visual system by the gyrus rectus. Case report. J Neurosurg. 1981;55(2):272-5.

5. Kennedy F. Retrobulbar neuritis as an exact diagnostic sign of certain tumors and abscesses in the frontal lobes. Am J Med Sci. 1911; 142(3):355-68

6. Behbehani R. Clinical approach to optic neuropathies. Clin Ophthalmol. 2007;1(3):233-46.

7. Vaphiades MS, Brodsky MC. Pediatric Optic Atrophy. Int Ophthalmol Clin. 2012;52(3):17-28.

8. Huna-Baron R, Lesser RL, Warren FA, Muszynski CA, Kupersmith MJ. Infantile cerebral aneurysms with visual pathway compression. Pediatr Neurosurg. 1999;31(6):322-5.

9. Ishikawa T, Tatsuhiko I, Eiichi S, Inukai K. Compressive optic nerve atrophy resulting from a distorted internal carotid artery. Pediatr Neurol. 2000;22:322-24. 